\title{
Assessing Racial Preferences in Movies: The Impact of Mere-Exposure and Social Identity Theory
}

\author{
Katherine Aumer, Devin Blas, Kelsea Huston, Christine Mabuti, Ning Hsu \\ Hawai'i Pacific University, Honolulu, HI, USA \\ Email: kaumer@hpu.edu
}

How to cite this paper: Aumer, K., Blas, D., Huston, K., Mabuti, C., \& Hsu, N. (2017). Assessing Racial Preferences in Movies: The Impact of Mere-Exposure and Social Identity Theory. Psychology, 8, 13141325.

https://doi.org/10.4236/psych.2017.89085

Received: June 13, 2017

Accepted: July 16, 2017

Published: July 19, 2017

Copyright $\odot 2017$ by authors and Scientific Research Publishing Inc. This work is licensed under the Creative Commons Attribution International License (CC BY 4.0).

http://creativecommons.org/licenses/by/4.0/

\begin{abstract}
Current media attention on the lack of racial diversity in the movie and TV industry in the US suggests that there is an innate bias of Whitewashing in the US media by media executives (Jones, 2016). However, some have suggested that the Whitewashing is an audience preference. Is the preference for White actors a product of bias by media executives or driven by audience preferences? This study tested whether social identity theory or the mere-exposure effect would have an impact on the racial preference of actors for monoracial People of Color, Multiracial, and White individuals. We found a preference for White actors and Whitewashing, but this preference was only found for Western stories and by monoracial People of Color Minorities when they were exposed to Asian actors. These findings suggest that other factors, specifically cultural values may be important in understanding preference for White actors in the media.
\end{abstract}

\section{Keywords}

Whitewashing, Mere-Exposure, Social Identity Theory, Asian, Movies, Diversity, Casting

\section{Introduction}

The prevalence of preferential casting of White individuals for minority roles in the United States (US) film industry has been termed: "Whitewashing" (Whitewashing, 2016). Whitewashing has been apparent in the US film industry early on (Scherker, 2014). Examples can be seen as early as 1921, when Rudolph Valentino played a man of Arab descent in The Shiek. More recent examples can be seen with Johnny Depp playing Tonto, a Native American in the Lone Ranger (2013) and Scarlett Johansson playing Kusanagi, a Japanese woman in Ghost in 
the Shell (2017). The arguments for why there is a preference for Whitewashing has targeted both movie producers who argue they would be unable to find financial support for their movies without casting predominantly White actors (Alexander, 2001; Horn, 2002; Samuels \& Leland, 1999) and also targeting White moviegoers, who perceive movies without White actors as not appealing to them or their identity (Weaver, 2011). However, recent criticism has put doubt to the idea that all White actors are financially necessary for successful movies (Chow, 2016). A recent report has found that more diverse casted films actually perform financially better than predominantly White casted films and that there are many all White films that financially fail (Hunt \& Ramon, 2015). Current continuation for Whitewashing in the US film industry could still be a product of industry habit; however, the argument that moviegoers prefer White actors is still tenuous and should be tested. Could it be that film industry executives are offering audiences predominantly White casted films because that is what the audiences want ("art reflecting life") or is the audience preferring White actors in their films because of the long history of seeing predominantly White actors in the movies ("life reflecting art")? The purpose of the following study is to answer this question.

\section{Theoretical Background}

Moviegoers may prefer to see movies with predominantly White actors because they are accustomed to seeing predominantly White actors in the movies and in the general media. Zajonc's $(1968,2001)$ theory of the mere-exposure effect would support this claim, suggesting that individuals continued exposure to a stimulus (in this case, White actors) would increase their liking of the stimulus in future events (i.e., White actors in future movies). If Whitewashing is preferred by moviegoers due to the mere-exposure effect, we should see that both White and monoracial People of Color audience members prefer White actors in their movies.

The impact of mere-exposure on people's preferences is not new to marketing and media studies. Research has shown that the impact of just exposing oneself repeatedly to a product can increase one's liking for that product, however there are moderating and mediating variables (Bornstein, 1989). For example, Cox and Cox (2002) found that preference for a product may be dependent on the perceived complexity of that product. Simple products or products with perceived simplicity seem to actually decrease one's liking of that product after repeated exposure. Similarly, when it comes to aesthetic preferences mere-exposure, alone, seems to be less effective at predicting one's choices than typicality or common representation (Martindale, Moore, \& West, 1988). Provided that White casts are the most simple and typical in Western movies, it may be that the preference for predominantly White casts may be not just a product of mere-exposure, but of simplicity and typicality. However, there is also research suggesting that novelty is an important factor in aesthetic preferences. Hekkert, Snelders, \& Wieringen (2003) have shown that both novelty and typicality (con- 
ceptually opposing concepts) actually work together to create aesthetic preferences. As long as the novelty does not infringe or negate typical representations of the product or concept, then novel items are preferred. Given these findings, one would think that racially diverse casts would be a preferred cast in many shows and movies as it may provide just enough novelty while not affecting the typicality of racial representation. Yet, we still do not see much racial diversity in casting choices.

Another psychological phenomenon may explain the continued Whitewashing in the film industry and this is Social Identity Theory (Tajfel, 1978). In Social Identity Theory, people's self-esteem is anchored in their social identities and thus positive representation of their social identities is necessary to maintain a positive self-esteem. Considering that racial identity is one of the predominant social categories in which people use to identify (Hewstone, Hantzi, \& Johnston, 1991), it should not be unusual to find that people prefer to see their racial group positively portrayed in the movies and media. There is research suggesting that people prefer to watch shows that are inclusive of their own gender (Oliver, 2000; Trepte, 2006) and culture (Zillmann et al., 1995). However, the research concerning in-group racial preference on casting choices is still nascent (Weaver, 2011). Weaver's (2011) studies demonstrated some credence to the argument that people prefer racial ingroup members in lead roles, however, this was only demonstrated for White individuals and other factors like genre of movie and celebrity of actors seemed to impact his findings. Additionally, Weaver (2011) found that colorblindness (Neville, Lilly, Duran, Lee, \& Browne, 2000) moderated the findings that Whites were more likely to prefer their racial ingroup in movies. Colorblindness is the endorsement that racial identity and membership have no consequence or impact in one's life; an incidentally ironic cognitive bias considering that such an endorsement is indicative of greater prejudice against people of color (Richeson \& Nussbaum, 2004). Supporting the association between colorblindness and prejudice, Weaver (2011) found that Whites with high levels of colorblindness were more likely to prefer movies with White casts than monoracial People of Color casts. Suggesting that Whitewashing may be explained by principles of social identity theory, at least for Whites. However, it is still unclear if monoracial People of Color or minorities have the same preferential bias for their own racial ingroup or, possibly, a preference for White casts.

Some evidence (e.g., Harris, 2016; Jones, 2016) has suggested that monoracial People of Color may actually prefer White casts, as has been argued by many entertainment executives who suggest that stories do not sell well overseas. For example, Marion Edwards, Fox's International TV President stated that diverse shows to not sell well overseas, because they do not reflect the society that those people live in: "These shows [diverse shows] are a reflection of our society, but [they are] not a reflection of all societies." She further states: "We are telling our units that they need to be aware that by creating too much diversity in the leads in their show means... problems having their shows translating to the international market." (Roxborough, 2016). If the level of diversity in a society is having 
an effect on the racial preference for actors, then we should be able to find this by sampling people from a diverse environment. If the reasoning that less diverse environments tend to create a preference for Whitewashing or White actors then we should see less preference for White actors in more diverse societies.

\section{The Present Study}

If Whitewashing is a product of "life reflecting art" we should see support for Zajonc's $(1968,2001)$ mere-exposure effect, in that both Whites and minorities endorse the casting of primarily White actors in their movies. However, if Whitewashing is a product of "art reflecting life" and social identity theory (Tajfel, 1978) is operating universally for both Whites and minorities when it comes to their preference for movies, then we should see that both Whites and minorities prefer their own ingroups to be cast. Additionally, by conducting this study in a racially diverse area we should be able to test if the preference for Whitewashing is at all impacted by the racial diversity of one's environment. The following study was conducted in order to better understand the operating principles behind Whitewashing from an audience standpoint that encompasses both majority (Whites) and minority audience members.

\section{Method}

\section{Participants and Procedures}

Participants were recruited from online social networks sites and at a university in Hawaii. Hawaii is known for its racial diversity and unlike the rest of the mainland US has no one racial majority (US Census Bureau, 2016). It is important to note that we were not measuring "Hawaiian" racial identity, but only how exposure to a racially diverse environment might affect one's preferences for media with racially diverse casts. Undergraduate psychology students at the university received course credit upon completion of the study, while all other participants received no compensation. The following study was approved by the Hawaii Pacific University Institutional Review Board. There were 228 (Female = 165 , Male $=63)$. The average age of participants was 21.42 years $(S D=5.06)$. Participants were asked to specify which racial group or groups they identified with. Considering that racial identity of participants is being used as the variable testing social identity theory, it is important to delineate how racial identity was measured. Participants could choose from a variety of racial groups including listing their own racial groups should one not be listed. Those that identified with more than one racial group, were automatically classified as "Multiracial". Those that identified with only one minority (i.e., not White) racial group were automatically classified as Monoracial People of Color (MPOC). The sample reflected a racially diverse population: $38 \%$ Multiracial, $32 \%$ MPOC (Asian $=46$, Hawaiian $=9$, Hispanic $=9$, and Black $=8$ ), and 30\% White.

Each participant completed an online self-report survey via Qualtrics. The 
participant filled out basic demographic information: gender, age, and ethnicity. The survey included questions measuring the amount and type of media watched and preferred. Example questions included: "In a typical week, how many hours of TV do you watch?" and "Which sources of entertainment do you use most often?".

After the demographic questions, participants were randomly assigned to one of three conditions: Asian cast, Black cast, or White cast. In each condition, participants were presented with four stories that were pre-selected for familiarity. Aladdin was chosen because a previous pre-study revealed that participants saw this film to be equally cast with monoracial People of Color actors. The four stories included: Aladdin (Clements \& Musker, 1992), Titanic (Cameron \& Landau, 1997), Harry Potter (Rowling, 2001), and The Little Mermaid (Clements \& Musker, 1989). The participants were given the description of the story, along with a pre-selected cast for each story. Those in the Asian cast condition were shown an Asian cast, those in the Black cast condition were shown a Black cast, and those in the White cast condition were shown a White cast. Actors and actresses were selected from IMDB database and the StarMeter was used to match actor's prominence across racial groups. Although we were able to match several White and Black actors (e.g., Johnny Depp and Will Smith) in concerns with their StarMeter profiles, this proved to be difficult for the Asian cast, as no Asian actors are currently considered as prominent as Johnny Depp or Will Smith. Participants in the Asian cast condition (StarMeter ratings in parentheses as of July 12, 2016) saw the following cast: Young Mermaid: Brenda Song (Top 5000), Sea Witch: Sandra Oh (Top 5000), Princess: Maggie Q. (Top 5000), Street Peddler: John Cho (Top 5000), Young Orphan Boy: Aaron Yoo (N/A), Evil Sorcerer: Daniel Dae Kim (Top 5000), Young Woman: Jamie Chung (Top 500), Poor Artist: Leonardo Nam (N/A). Participants in the Black cast condition saw the following actors: Young Mermaid: Keke Palmer (Top 5000), Sea Witch: Oprah (Top 5000), Princess: Katarina Graham (N/A), Street Peddler: Michael B. Jordan (Top 5000), Young Orphan Boy: Corbin Bleu (Top 5000), Evil Sorcerer: Will Smith (99), Young Woman: Zoe Saldana (Top 500), Poor Artist: Brian White (N/A). Participants in the White cast condition saw this cast: Young Mermaid: Emma Stone (95), Sea Witch: Jennifer Love-Hewitt (Top 500), Princess: Chloe Moretz (32), Street Peddler: Zac Efron (100), Young Orphan Boy: Josh Hutcherson (Top 5000), Evil Sorcerer: Johnny Depp (87), Young Woman: Amanda Seyfried (Top 500), Poor Artist: Liam Hemsworth (85).

Participants reported their willingness to watch the movie and to predict the likelihood of the movies success using a 7-point Likert Scale. For example, the participants were asked, "How likely are you to watch this movie with the chosen cast?" based on a scale from (1) "Very Unlikely" to (7) "Very Likely".

The second part of the study, also called the "participant casted" part of the study, asked participants to cast their own actors and actresses. Participants were given separate stories (again pre-selected for familiarity) and possible actors (pre-selected to be similar in terms of fame) from three different racial groups 
(Asian, Black, and White). Participants were told they could cast their own actors and actresses from a possible list of actors and actresses. Additionally, participants saw photos of the actors and actresses (retrieved from IMDB.com). If former exposure to the minority casts (Asian, Black, White) had any impact on their casting choices in this part of the experiment, we would be able to test this and show confirmation or disconfirmation of a mere-exposure effect. The stories presented included Holes (Davis et al., 2003), Mulan (Murphy et al., 2013), Robin Hood (Burrows, Corvino, \& Pyle, 2005), Rumpelstiltskin (Hunt, 1944), and The Pursuit of Happyness (Gardner, 2006). Stories were chosen after a pre-test revealed that these were the most well known stories. We were specifically looking to see if any Whitewashing would appear in the story of Mulan and The Pursuit of Happyness. The participants were able to cast two actors per story and could choose from Asian, Black, or White actors/actresses; all actors and actresses that were previously presented in the pre-casted portion of the study were available for casting. Participants indicated their happiness with their choice for each story's cast with questions including, "How happy are you with this cast?" and "How likely do you think others will watch this movie considering the cast you have selected?". Participants answered from (1) "Very Unhappy/Unlikely" to (7) "Very Happy/Likely"At the end of the study, participants were debriefed and thanked for their time.

\section{Results}

\subsection{Testing for Preference for Whitewashed casts}

To test if participants preferred White and Whitewashed casts for the pre-casted stories, we conducted a $3 \times 3 \times 2$ MANOVA with the first factor being Race of participant (Monoracial monoracial People of Color, Multiracial, and White), the second factor being Condition (Asian cast, Black cast, White cast), the third factor being Media exposure (measured as a median split of hours per week spent watching media), and the dependent variables were likelihood of watching the pre-casted movies. If social identity theory is driving the preference for Whitewashing or White casted shows, we should see a significant interaction of Race and Condition on preference for movie, such that participants will be more likely to say they will watch a movie if they are presented with a cast that is similar to their own race. If the mere-exposure effect is driving the preference for Whitewashing, then we should see a main effect for Media exposure, such that those who score high on Media exposure will be more likely to say they would watch movies that are Whitewashed or with an exclusively White cast.

The main effect for Race of participant was significant for 2 movies: the likelihood of watching the movie Titanic $\left(F(2,189)=3.17, p=.04, \eta^{2}=.03\right)$ and the likelihood of watching the movie The Little Mermaid $(F(2,189)=2.98, p=.05$, $\left.\eta^{2}=.03\right)$. Post-hoc analysis with Bonferroni adjustment revealed that Multiracial participants were more likely to report wanting to watch Titanic ( $M=5.13, S E$ $=.22$ ) and The Little Mermaid $(M=4.95, S E=.23)$ than their White peers ( $T i$ tanic. $M=4.34, S E=.24$; Little Mermaid: $M=4.13, S E=.25)$. There was no sig- 
nificant difference between Whites and monoracial People of Color or monoracial People of Color and Multiracials in their preference for watching any of the pre-casted movies. With the exception of Aladdin $\left(F(2,189)=1.52, p=.22, \eta_{p}^{2}\right.$ $=.02$ ), all movies (Titanic: $F(2,189)=3.88, p=.02, \eta_{p}^{2}=.04$ ) (Harry Potter: $\left.F(2,189)=4.63, p=.01, \eta_{p}^{2}=.05\right)$ (Little Mermaid: $F(2,189)=5.39, p=.005$, $\left.\eta_{p}^{2}=.05\right)$ were impacted by Condition, or the race of the casted actors. Post-hoc analysis using Bonferroni correction, revealed that Whites were preferred as the cast for stories like Titanic $(M=5.20, S E=.22)$ and Harry Potter $(M=4.78, S E$ $=.23$ ) over Asian casts (Titanic: $M=4.39, S E=.23$; Harry Potter: $M=3.75, S E$ $=.25$ ), however there was no statistically significant difference between White and Black casts for these movies. For the movie The Little Mermaid, an Asian cast $(M=4.99, S E=.24)$ was preferred over a Black cast $(M=3.90, S E=.24)$, but there was no significant difference between Asian or White casts. See Figure 1 for an illustration of differences between the pre-casted movies. Media exposure (low vs high) and the interactions were not statistically significant in predicting any of the dependent variables.

\subsection{Testing for Whitewashing in Participant Casting}

During the second section of the study, participants could choose to cast their own characters. For the story of Rumpelstiltskin, $48 \%$ of participants chose a White cast, followed by $36 \%$ Multiracial cast and 16\% Minority cast. For the story of Holes, $46 \%$ of participants chose a Minority cast, $32 \%$ chose a Multiracial cast, and $22 \%$ chose a White cast. For the story of Mulan, $90 \%$ chose a Minority cast, $8 \%$ chose a Multiracial cast, and $2 \%$ chose a White cast. For the story of Robin Hood, 56\% chose a Multiracial cast, 33\% chose a Minority cast, and $11 \%$ chose a White cast. For the story of the Pursuit of Happyness, $56 \%$ chose a Minority cast, $39 \%$ chose a Multiracial cast, and $2 \%$ chose a White cast.

To test if Whitewashing was preferred for the "participant casted" part of the study, we first calculated the frequency of Asians, Blacks, and Whites casted by

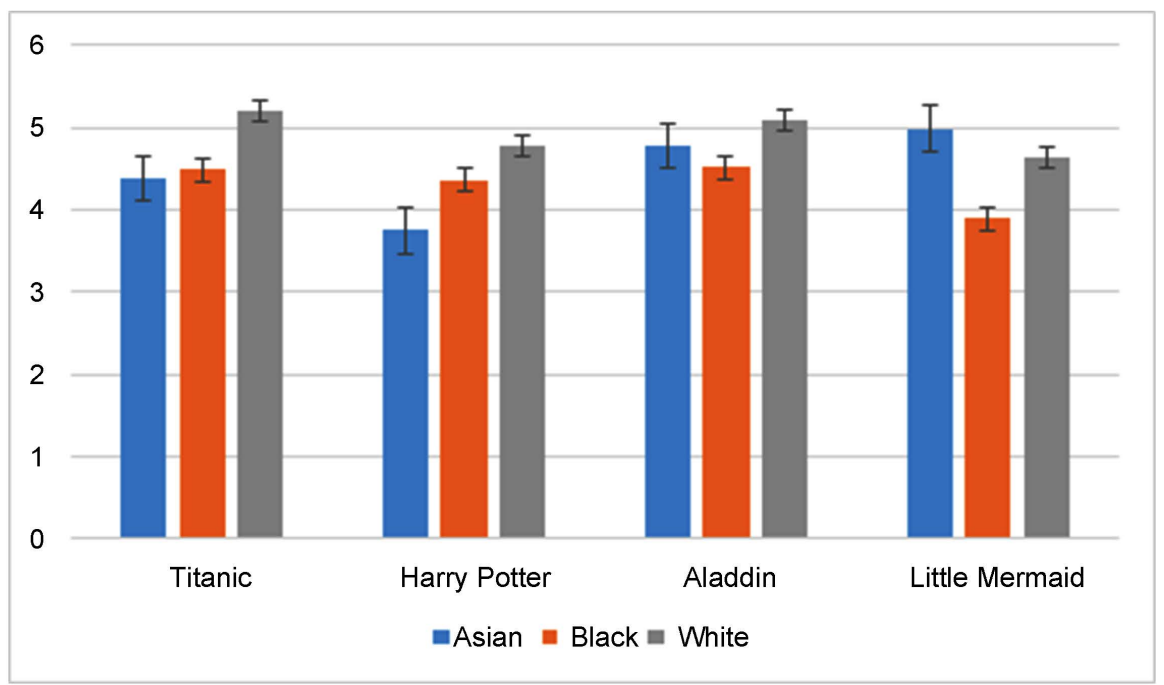

Figure 1. Preference for Asian, Black, or White casts across four different movies. 
each participant. We then conducted a $3 \times 3 \times 2$ MANOVA, with race of participant (Multiracial vs monoracial People of Color vs White), Condition of previous study (Asian vs Black vs White cast) and media usage (Low vs High) as the predictors and the frequency of casting an Asian, Black or White actor as the dependent variables. If social identity theory is driving preference for casting or preferring a certain race, then we should see the race of participant as a statistical predictor. If mere-exposure is driving preference for casting or preferring a certain race, we should see Condition and/or media exposure as a statistically significant predictor. Interestingly, the only statistically significant predictor of casting White actors was the interaction of participant race and Condition or the race of the previously casted condition in the beginning of the study $(F(4,162)=$ 3.42, $p=.01, \eta_{p}^{2}=.08$ ). Simple slopes tests using the Process macro in SPSS revealed that when monoracial People of Color were previously exposed to an Asian cast, they preferred White casts more $(M=1.38, S E=.15)$ than their peers who were previously exposed to Black $(M=0.65, S E=.75)$ or White $(M=0.75$, $S E=.17)$ casts. None of the other comparisons were significant.

To test if the race of the cast chosen by participants affected how happy they were with the cast and how likely they thought others would see the movie, we conducted a series of MANOVAs, using their happiness with chosen cast and likelihood that others would see the movie as dependent variables. We then used race of the cast as a predictor. Race of the actors chosen by participants was not statistically significant in predicting their happiness with the cast or their belief in the likelihood that others would see the movie ( $p s>.05)$.

\section{Discussion}

Is Whitewashing a product of bias by media executives or audience preference? The main objective of this study was to test if mere-exposure (Zajonc, 1968, 2001), measured as the amount of media exposure participants reported, or social identity theory (Tajfel, 1978) measured as racial identity, could predict the preference for Whitewashing or White actors. Interestingly, our studies findings did not show support for social identity theory, thus audience members are not preferring their own race when watching shows or movies. Participants did not prefer actors of their own race when shown pre-casted shows or when they were able to cast their own shows. However, we did reveal an anti-Asian bias. In the first part of our study, participants preferred shows that presented either White or Black actors over Asian actors. However, this was only true for stories in which the characters are traditionally White: Harry Potter, Titanic, and the Little Mermaid. The story of Aladdin showed no preference for race of actor. Considering that Aladdin is a traditionally middle eastern folktale, it is not surprising that participants seem to have no racial preference for the actors, since we did not provide any Middle Eastern actors. Given social identity theory and that our sample's monoracial People of Color population was mostly Asian, one might expect that these individuals would have shown a preference for the Asian actors in the pre-casted stories. Instead, all participants, despite their race, had a rejec- 
tion for Asian actors. Although stories like Harry Potter, Titanic, and the Little Mermaid are traditionally White stories, participants seemed equally likely to watch that story if it was cast with Black actors. Additionally, the mere-exposure effect did not seem to provide a clear rationale for these findings either, as participant's previously reported media exposure was not related to their preference for actors of a certain race.

The second part of the study revealed an even more surprising result when monoracial People of Color participants (who again are mostly Asian), seemed to prefer casting White actors after seeing shows with only Asian actors; showing some support for the mere-exposure effect. Interestingly, there was no preference for White actors when monoracial People of Color participants initially saw a Black cast or a White cast in the first part of the study; the preference for White actors by monoracial People of Color was only evident after seeing Asian actors. Some media attention has been given to the idea that Hollywood cannot sell shows with racially diverse casts to overseas markets, specifically Asia and Europe (Harris, 2016; Roxborough, 2016). Marion Edwards, Fox's International TV President, suggested that the lack of profitability in foreign markets may be due to a lack of diversity in these areas (Jones, 2016). However, our sample from Hawaii, is located in a racially diverse area (US Census Bureau, 2016). It appears that neither the racial diversity of an area nor social identity theory seem to be good predictors of an anti-Asian bias. Instead, it seems that mere-exposure; when measured as immediate exposure to actors of Asian descent and not previous time watching popular media (TV and film), may be driving a White preference or anti-Asian bias.

Some possible reasons for why, specifically Asians preferred White actors after viewing Asian actors may be rooted in findings from marketing and relationships research that have revealed a "White bias" for Asians. Specifically, Asian culture emphasizes whiteness and fairness as a form of beauty; skin whitening creams are sold routinely in order to enhance one's attractiveness, especially for women (Li et al., 2008). Additionally, Asian women have a high percentage of interracial dating and those who do date interracially, are more likely to date White men than any other racial group (Mok, 1999). The Asian obsession with Whiteness may be an important element for how Asians see themselves and the entertainment they prefer.

\section{Limitations of This Study}

This study has several limitations that are important to address in future research. The first limitation was that the stories in the study were mostly known by or a reflection of Western values and thoughts. Although we did specifically choose three Non-Western stories: Aladdin, Mulan, and The Pursuit of Happyness to test for Whitewashing, these stories are still prevalent in Western culture and participants may have been influenced by previous media exposure.

Future research should consider measuring participants' cultural values and admiration for White culture. Although Weaver (2011) found that colorblind- 
ness was related to White preference of actors, colorblindness is positively related to prejudice and is not necessarily related to White admiration. White admiration or valuing of Whiteness may be an important element when considering the preference of White actors, especially by monoracial People of Color audience members.

Finally, this study is the only study that we know that addresses both majority and minority racial preference for actors. Most studies on diversity are concerned with the impact diversity has on White individuals (see Rattan \& Ambady, 2013, for a review), however, considering the growing diversity of the US (Colby \& Ortman, 2014) and current rates of globalization, future research needs to consider and investigate how minorities are impacted by the growth in diversity and their representation in the media.

\section{References}

Alexander, G. (2001). Reaching the Silver Screen. Black Enterprise. http://www.blackenterprise.com/mag/reaching-the-silver-screen/

Bornstein, R. F. (1989). Exposure and Affect: Overview and Meta-Analysis of Research, 1968-1987. Psychological Bulletin, 106, 265. https://doi.org/10.1037/0033-2909.106.2.265

Burrows, J., Corvino, L., \& Pyle, H. (2005). The Adventures of Robin Hood. New York: Sterling Pub.

Cameron, J., \& Landau, J. (1997). Titanic [Motion Picture]. United States: Paramount Pictures.

Chow, K. (2016). Why Won't Hollywood Cast Asian Actors. The New York Times. http://www.nytimes.com/2016/04/23/opinion/why-wont-hollywood-cast-asian-actors. $\underline{\mathrm{html}}$

Clements, R., \& Musker, J. (1989). The Little Mermaid [Motion Picture]. United States: Buena Vista Pictures.

Clements, R., \& Musker, J. (1992). Aladdin [Motion Picture]. United States: Buena Vista Pictures.

Colby, S. L., \& Ortman, J. M. (2014). Projections of the Size and Composition of the U.S. Population: 2014 to 2060, Current Population Reports, P25-1143. Washington DC: Census Bureau.

https://www.census.gov/content/dam/Census/library/publications/2015/demo/p25-114 3.pdf

Cox, D., \& Cox, A. D. (2002). Beyond First Impressions: The Effects of Repeated Exposure on Consumer Liking of Visually Complex and Simple Product Designs. Journal of the Academy of Marketing Science, 30, 119-130.

https://doi.org/10.1177/03079459994371

Davis, A. Blank, L., Davis, A., \& Medavoy, M. (2003). Holes [Motion Picture]. USA: Buena Vista Pictures Distribution.

Gardner, C. (2006). The Pursuit of Happyness. New York: Amistad.

Harris, A. (2016). Industry Folks Are Really Trying to Make the "Diversity Doesn't Sell Overseas" Mantra Happen.

http://www.slate.com/blogs/browbeat/2016/03/30/the_hollywood_reporter_on_empire s_global_ratings_is_the_latest_attempt.html

Hekkert, P., Snelders, D., \& Wieringen, P. C. (2003). "Most Advanced, Yet Acceptable": 
Typicality and Novelty as Joint Predictors of Aesthetic Preference in Industrial Design. British Journal of Psychology, 94, 111-124. https://doi.org/10.1348/000712603762842147

Horn, J. (2002). A Majority Audience for "Minority" Films. Los Angeles Times, 16 December 2002. http://articles.latimes.com/2002/dec/16/entertainment/et-horn16

Hunt, D., \& Ramon, A. (2015). 2015 Hollywood Diversity Report: Flipping the Script. http://www.bunchecenter.ucla.edu/wp-content/uploads/2015/02/2015-Hollywood-Div ersity-Report-2-25-15.pdf

Hunt, M. (Translator) (1944). The Complete Grimm's Fairy Tales. New York: Pantheon Books.

Jones, K. (2016). Report: Hollywood Diversity Push Fails Abroad; "Empire” a "Global Flop".

http://www.breitbart.com/big-hollywood/2016/03/30/report-foreign-audiences-resist-h ollywood-diversity-push-empire-a-global-flop/

Li, E. P., Min, H. J., Belk, R. W., Kimura, J., \& Bahl, S. (2008). Skin Lightening and Beauty in Four Asian Cultures. In A. Y. Lee, \& D. Soman (Eds.), NA-Advances in Consumer Research (Vol. 35, pp. 444-449). Duluth, MN: Association for Consumer Research. http://www.acrwebsite.org/volumes/13415/volumes/v35/NA-35

Martindale, C., Moore, K., \& West, A. (1988). Relationship of Preference Judgments to Typicality, Novelty, and Mere Exposure. Empirical Studies of the Arts, 6, 79-96. https://doi.org/10.2190/MCAJ-0GQT-DJTL-LNQD

Mok, T. A. (1999). Asian American Dating: Important Factors in Partner Choice. Cultural Diversity and Ethnic Minority Psychology, 5, 103-117. https://doi.org/10.1037/1099-9809.5.2.103

Murphy, E., Ferrer, M., Liu, L., Takei, G., Wen, M.-N., \& Bd, W. (2013). Mulan. United States: Disney.

Neville, H. A., Lilly, R. L., Duran, G., Lee, R. M., \& Browne, L. (2000). Construction and Initial Validation of the Color-Blind Racial Attitudes Scale (CoBRAS). Journal of Counseling Psychology, 47, 59-70. https://doi.org/10.1037/0022-0167.47.1.59

Oliver, M. B. (2000). The Respondent Gender Gap. In D. Zillmann, \& P. Vorderer (Eds.), Media Entertainment: The Psychology of Its Appeal (pp. 215-234). Mahwah, NJ: Lawrence Erlbaum Associates.

Rattan, A., \& Ambady, N. (2013). Diversity Ideologies and Intergroup Relations: An Examination of Colorblindness and Multiculturalism. European Journal of Social Psychology, 43, 12-21. https://doi.org/10.1002/ejsp.1892

Richeson, J. A., \& Nussbaum, R. J. (2004). The Impact of Multiculturalism versus Color-Blindness on Racial Bias. Journal of Experimental Social Psychology, 40, 417-423. https://doi.org/10.1016/j.jesp.2003.09.002

Rowling, J. K. (2001). Harry Potter and the Prisoner of Azkaban. New York: Scholastic Paperbacks.

Roxborough, S. (2016). America's TV Exports Too Diverse for Overseas? http://www.hollywoodreporter.com/news/americas-tv-exports-diverse-overseas-879109

Samuels, A., \& Leland, J. (1999). They've Got Next: Today's Young Black Pack Learns to Stand up against the Same Old Hollywood Hang-Ups-and the New Box-Office Jitters Caused by "Beloved"(pp. 58-60). Newsweek, 5 April 1999.

Scherker, A. (2014). Whitewashing Was One of Hollywood's Worst Habits. So Why Is It Still Happening? The Huffington Post.

http://www.huffingtonpost.com/2014/07/10/hollywood-whitewashing_n_5515919.html

Tajfel, H. E. (1978). Differentiation between Social Groups: Studies in the Social Psychol- 
ogy of Intergroup Relations. Cambridge, MA: Academic Press.

Trepte, S. (2006). Social Identity Theory. In J. Bryant, \& P. Vorderer (Eds.), Psychology of Entertainment (pp. 255-271). Mahwah, NJ: Lawrence Erlbaum Associates Publishers.

US Census Bureau (2016). Quick Facts: Hawaii. US Census Bureau Website. https://www.census.gov/quickfacts/fact/table/HI/PST045216

Weaver, A. J. (2011). The Role of Actors' Race in White Audiences' Selective Exposure to Movies. Journal of Communication, 61, 369-385. https://doi.org/10.1111/j.1460-2466.2011.01544.x

Whitewashing (2016). Wikipedia. https://en.wikipedia.org/wiki/Whitewashing_in_film

Zajonc, R. B. (1968). Attitudinal Effects of Mere Exposure. Journal of Personality and Social Psychology, 9, 1-27. https://doi.org/10.1037/h0025848

Zajonc, R. B. (2001). Mere Exposure: A Gateway to the Subliminal. Current Directions in Psychological Science, 10, 224-228. https://doi.org/10.1111/1467-8721.00154

Zillmann, D., Aust, C. F., Hoffman, K. D., Love, C. C., Ordman, V. L., Pope, J. T. et al. (1995). Radical Rap: Does It Further Ethnic Division? Basic and Applied Social Psychology, 16, 1-25. https://doi.org/10.1080/01973533.1995.9646098

Submit or recommend next manuscript to SCIRP and we will provide best service for you:

Accepting pre-submission inquiries through Email, Facebook, LinkedIn, Twitter, etc. A wide selection of journals (inclusive of 9 subjects, more than 200 journals) Providing 24-hour high-quality service User-friendly online submission system Fair and swift peer-review system Efficient typesetting and proofreading procedure Display of the result of downloads and visits, as well as the number of cited articles Maximum dissemination of your research work

Submit your manuscript at: http://papersubmission.scirp.org/

Or contact psych@scirp.org 